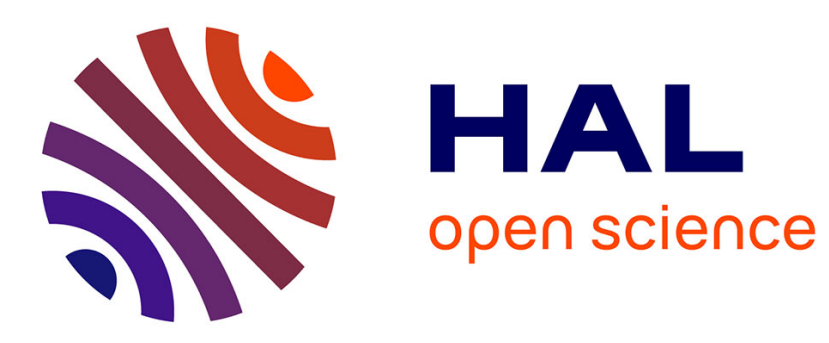

\title{
An integrated risk index accounting for epistemic uncertainty in probability risk assessment
}

Zhiguo Zeng, Tasneem Bani-Mustafa, Roger Flage, Enrico Zio

\section{To cite this version:}

Zhiguo Zeng, Tasneem Bani-Mustafa, Roger Flage, Enrico Zio. An integrated risk index accounting for epistemic uncertainty in probability risk assessment. Proceedings of the Institution of Mechanical Engineers, Part O: Journal of Risk and Reliability, 2021, 235 (4), pp.711-728. 10.1177/1748006X20968954 . hal-03464071

\section{HAL Id: hal-03464071 \\ https://hal.science/hal-03464071}

Submitted on 2 Dec 2021

HAL is a multi-disciplinary open access archive for the deposit and dissemination of scientific research documents, whether they are published or not. The documents may come from teaching and research institutions in France or abroad, or from public or private research centers.
L'archive ouverte pluridisciplinaire HAL, est destinée au dépôt et à la diffusion de documents scientifiques de niveau recherche, publiés ou non, émanant des établissements d'enseignement et de recherche français ou étrangers, des laboratoires publics ou privés. 


\title{
An integrated risk index accounting for epistemic uncertainty in Probability Risk Assessment (PRA)
}

\author{
Zhiguo Zeng ${ }^{1 *}$, Tasneem Bani-Mustafa ${ }^{1}$, Roger Flage ${ }^{2}$, Enrico Zio ${ }^{3,4}$ \\ ${ }^{1}$ Université Paris Saclay, CentraleSupélec, Laboratoire Genie Industriel, \\ Chaire on Risk and Resiliecne of Complex Sysems, Gif-sur-Yvette, France \\ ${ }^{2}$ University of Stavanger, Norway \\ ${ }^{3}$ MINESParisTech,PSLResearchUniversity,CRC,SophiaAntipolis,France \\ ${ }^{4}$ Energy Department, Politecnico di Milano, Milan, Italy \\ *: zhiguo.zeng@centralesupelec.fr
}

\begin{abstract}
In this paper, we present an integrated framework for quantifying epistemic uncertainty in probabilistic risk assessment. Three types of epistemic uncertainty, i.e., completeness, structural and parametric uncertainties, are considered. A maturity model is developed to evaluate the management of these epistemic uncertainties in the model building process. The impact of epistemic uncertainty on the result of the risk assessment is, then, estimated based on the developed maturity model. Then, an integrated risk index is defined to reflect the epistemic uncertainty in the risk assessment results. An indifference method is developed to evaluate the index based on the maturity of epistemic uncertainty management. A case study concerning a nuclear power plant is shown to demonstrate the applicability of the overall modelling framework.
\end{abstract}

\section{Highlights}

- A maturity model is developed to evaluate the management of epistemic uncertainty in the probabilistic risk assessment model building process.

- An integrated risk index is defined to reflect epistemic uncertainty in probabilistic risk assessments.

- An indifference method is developed to evaluate the integrated risk index.

- An application to a real nuclear power plant PRA is performed.

\section{Keywords}

Probabilistic Risk Assessment (PRA), epistemic uncertainty, aleatory uncertainty, maturity model, integrated risk index, indifference method, nuclear power plant

\section{Acronyms}

$\mathrm{BE}$

Basic Event 


$\begin{array}{ll}\text { MM-EU } & \text { Maturity Model for EU management } \\ \text { CDF } & \text { Cumulative Distribution Function } \\ \text { EDF } & \text { Electricité De France } \\ \text { EU } & \text { Epistemic Uncertainty } \\ \text { EUF } & \text { Epistemic Uncertainty Factor } \\ \text { EUM } & \text { Epistemic Uncertainty Management } \\ \text { NPP } & \text { Nuclear Power Plant } \\ \text { NRC } & \text { U.S. Nuclear Regulation Commission } \\ \text { MCS } & \text { Minimal Cut Set } \\ \text { PRA } & \text { Probabilistic Risk Assessment }\end{array}$

\section{Notation}

$\epsilon_{e} \quad$ Adjustment factor for epistemic uncertainty

$M_{E U M} \quad$ Maturity of epistemic uncertainty management

$\operatorname{Risk}_{P}^{*} \quad$ Conventional risk index in PRA

$d_{P} \quad$ Distance to the failure region for $\operatorname{Risk}_{P}$

$d_{B} \quad$ Distance to the failure region for Risk $_{B}$

$S_{E} \quad$ Equivalent safety margin

$\alpha_{e} \quad$ Epistemic uncertainty factor

$\mu_{S_{E}} \quad$ Mean value of the distribution of $S_{E}$

$\sigma_{S_{E}} \quad$ Standard deviation of the distribution of $S_{E}$ 


\section{Introduction}

In probabilistic risk assessment (PRA), risk indexes (e.g., the frequency of a given consequence, like core damage in a nuclear power plant (NPP)) are calculated using models that describe the occurrence and evolution of an accident ${ }^{1}$. It is well known that epistemic uncertainty (EU) exists in these models, referring to the uncertainty that results from incomplete/insufficient knowledge and/or approximations of the processes involved in the accidents ${ }^{2}$. As the risk indexes are results obtained from the knowledge in the PRA models, EU can significantly affect them. This is the reason why treatment of EU in PRA has been considered since the early days of PRA practice. For example, the U.S. nuclear regulation commission (NRC) formed a committee to review the PRA of WASH-1400 reactor and concluded that although the PRA is in general well-done, it does not adequately consider the uncertainty, especially epistemic uncertainty in the analysis ${ }^{3}$. Consequently, the NRC included a mandate to direct the NUREG-1150 PRAs, which emphasizes the need to include an assessment of epistemic uncertainty in the results of the PRA. Procedures were, then, developed and employed to characterize epistemic uncertainty in the NUREG-1150 PRAs, and, more generally, in PRAs for complex systems ${ }^{4}$. From a methodological framework point of view, Kaplan and Garrick 5 has suggested a "probability of frequency" framework where the frequency of a scenario considered in the risk assessment is assumed to be an uncertain quantity and the EU related to it is described by a (subjective) probability distribution. This formulation that separates aleatory and epistemic uncertainty has been widely applied, e.g., in the NRC regulations for the geologic disposal of radioactive waste ${ }^{6}$. Pate-Cornell ${ }^{7}$ characterized different levels of uncertainty treatment and considered the "probability of frequency" framework suitable for a full description of the uncertainty involved in PRA. Directly applying these frameworks in practice, however, is sometimes difficult, as it is not easy to determine the required probability distributions representative of the actual state of EU.

For the practical assessment of EU in PRA, in the present paper, we adopt the common classification, which distinguishes the following three categories of EU, based on their sources: completeness uncertainty, model structural uncertainty and parametric uncertainty ${ }^{8}$. Completeness uncertainty refers to the uncertainty caused by the factors that are not included in the PRA; model structural uncertainty results from the way the PRA model describes the physical features of the processes involved; parametric uncertainty results from the model parameter value estimation 8. Different methods have been developed in recent years for the assessment and characterization of the EU from the different sources (a more detailed review is presented in Sect. 2). Typically, in the existing works, the three sources of EU are considered separately, using different $a d$ hoc methods. A unified method for quantifying the EU collectively, would be useful for a complete characterization of the uncertainty in the PRA models. 
In this paper, we present a unified framework for quantifying EU in PRA, based on a maturity model designed to evaluate the management of epistemic uncertainty in a PRA model building process. An integrated risk index is defined to reflect EU in risk assessment. Considering the existing frameworks for quantifying EU, the contributions of the present work are:

- A collective assessment of completeness, model structural and parametric uncertainty is given by the developed maturity model.

- An integrated risk index is defined to consider the collective effect of EU on the PRA results.

- A practical procedure is presented to consider EU in PRA, based on the maturity model of EU management.

The rest of the paper is organized as follows. Sect. 2 reviews works related to quantifying EU in PRA. A maturity model is developed in Sect. 3 to evaluate the capability of managing EU in a PRA. In Sect. 4, a new risk index is introduced for reflecting EU in a PRA. To evaluate the risk index using the maturity model, an indifference method is developed in Sect. 4. A case study of a Nuclear Power Plant (NPP) is conducted in Sect. 5. Finally, the paper is concluded in Sect. 6, with some discussions on potential future works.

\section{Literature review}

In this section, we review existing approaches for quantifying EU in PRA. There are different ways of classifying EU in literature. For example, Knight ${ }^{9}$ distinguished two types of uncertainties: unquantifiable (where precise probabilistic quantification cannot be obtained) and quantifiable (where probabilities are available). The latter is also referred to as "(decision making under) risk" and the former as "(decision making under) uncertainty". Wynne ${ }^{10}$ argued that risk assessments are conditioned on assumptions and categorized the EU by examining the degree of appropriateness of these assumptions. Apart from the "risk" and "uncertainty", it was proposed to consider the two other types of uncertainties: ignorance, which corresponds to a state that “we don't know what we don't know about the completeness and validity of our knowledge" and indeterminacy, which arises when the causal chains or networks in the problems are still open ${ }^{10}$. Another widely accepted categorization is to distinguish between conscious ignorance (knowing that you don't know) and blind ignorance (not knowing that you don't know, also called metaignorance) ${ }^{11}$. Based on the object of the uncertainties, Spiegelhalter and Riesch ${ }^{12}$ defined a five-level structure for assessing and communicating uncertainties: (uncertainties in) events, model parameters, alternative model structures, model inadequacy from recognized sources and model inadequacy from unspecified sources. The first type is mainly aleatory uncertainty while the rest four belong to EU.

We can go on with the discussions on EU classifications: there are many ways of categorization and no real 
agreements exist on how to do so. In this paper, we follow the operational perspective of the US Nuclear Regulatory Commission and classify EU into completeness uncertainty, model structural uncertainty and parametric uncertainty, as shown in Figure $1^{8}$. This classification is associated with different phases of PRA modelling and analysis: completeness uncertainty concerns if some dangerous hazards or initiating events are missed in the analysis; model structural uncertainty is about the adequacy of the used model to describe the phenomena involved; parametric uncertainty is about the accuracy of model parameters. The classification results from the work of researchers and practitioners in the field of risk assessment. For example, Kaplan and Garrick ${ }^{5}$ pointed out that risk analysis is essentially a listing of scenarios that could lead to accidents, but the scenarios covered by the analysis are inevitably incomplete, leading to completeness uncertainty. Apostolakis ${ }^{13}$ discussed the uncertainties in modelling and distinguished between two types of state-of-knowledge uncertainties: uncertainties about model assumptions and uncertainties about model parameters, which correspond to the model structural and parametric uncertainty, respectively. The reason for us to adopt this classification framework is that it provides an operational way to separate the different contributors to EU in the PRA models, which is usable in practice for supporting EU management. It should be noted that this classification is based on the object of EU and not on its sources. It does not contradict with the classification of ${ }^{11}$ : both completeness, model structural and parametric uncertainty might be caused by either conscious or blind ignorance, as shown in Figure 2. To better explain this, we give examples for the different combinations of uncertainty types in Table 1.

The following sections (Sects 2.1-2.3), then, review the methods used for characterizing each of these three types of EU, respectively. Please note that there exist other taxonomy schemes for epistemic uncertainty. We choose the one based on ${ }^{8}$ as it fits more the operative treatment of the epistemic uncertainty in PRA.

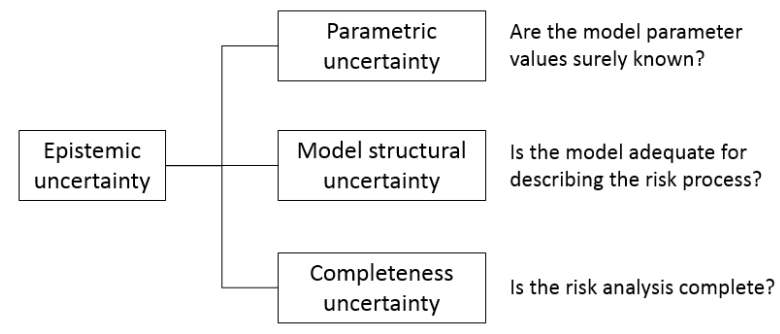

Figure 1 A classification of EU in PRA. 


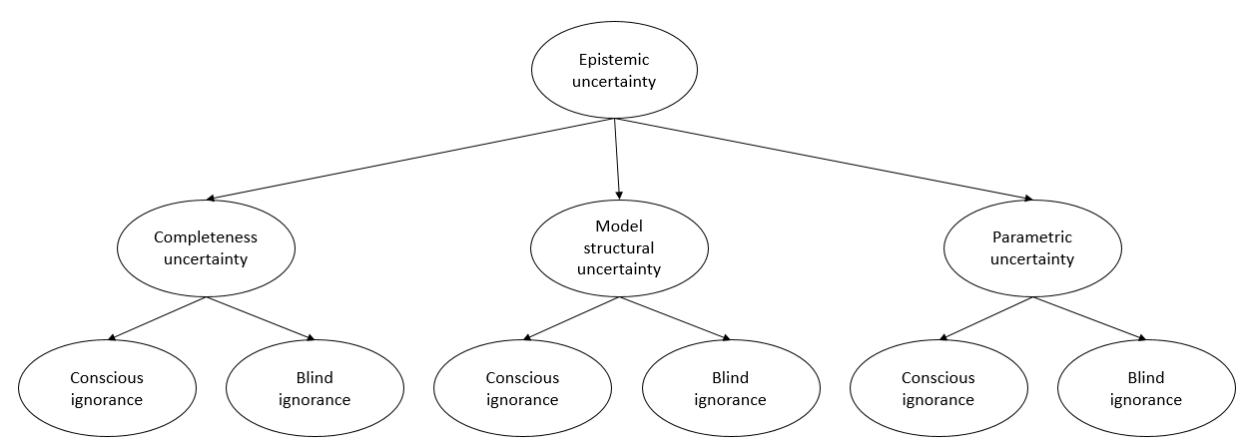

Figure 2 Relationship between different uncertainty types.

Table 1 Examples of different combination of uncertainty types.

\begin{tabular}{|l|l|l|}
\hline \multicolumn{1}{|c|}{$\begin{array}{l}\text { Smith- } \\
\text { Son's }\end{array}$} & Conscious ignorance & Blind ignorance \\
\hline $\begin{array}{l}\text { Completeness } \\
\text { uncertainty }\end{array}$ & $\begin{array}{l}\text { consider a scenario as irrelevant and } \\
\text { exclude it from the PRA on purpose. } \\
\text { But the scenario turns out to be } \\
\text { important and leading to accidents. }\end{array}$ & $\begin{array}{l}\text { In the 1950s, two consecutive mid-air explosions of the } \\
\text { airplane De Havilland Comet occurred, which were } \\
\text { found out to be caused by metal fatigue. Before these } \\
\text { accidents, people did not understand that metal fatigue } \\
\text { could occur in such a manner as what happened in De } \\
\text { Havilland Comet. If we were to perform a PRA for } \\
\text { airplanes before the De Havilland Comet accidents, metal } \\
\text { fatigue would have been ignored, as an example of this } \\
\text { category. }\end{array}$ \\
\hline $\begin{array}{l}\text { Model } \\
\text { structural } \\
\text { uncertainty }\end{array}$ & $\begin{array}{l}\text { In developing a model, we } \\
\text { purposely select a linear model to } \\
\text { approximate a non-linear process, } \\
\text { because we think that the } \\
\text { inaccuracy is tolerable, considering } \\
\text { the gains in saving modelling } \\
\text { complexity. }\end{array}$ & $\begin{array}{l}\text { We failed to notice that the actual process is non-linear, } \\
\text { and we select a linear model for modelling the process } \\
\text { with unknown non-linear effects. }\end{array}$ \\
\hline $\begin{array}{l}\text { Parametric } \\
\text { uncertainty }\end{array}$ & $\begin{array}{l}\text { We select a limited sample size for } \\
\text { parameter estimation and } \\
\text { understand the uncertainty might be } \\
\text { caused by such a small sample size. }\end{array}$ & $\begin{array}{l}\text { We think that the sample size for parameter estimation is } \\
\text { large enough so that the estimation is accurate, whereas, } \\
\text { in reality, the estimation is still subject to uncertainty due } \\
\text { to the unnoticed fact the sample size for estimation is not } \\
\text { sufficient. }\end{array}$ \\
\hline
\end{tabular}

\subsection{Completeness uncertainty}

Completeness uncertainty results from the fact that the PRA might be incomplete and fail to consider some important risk contributors ${ }^{8}$. This might result in underestimation of risk ${ }^{14}$. Terms and concepts used in the literature in relation to completeness uncertainty include ignorance, surprising events, black swan ${ }^{15}$, etc.

Unforeseen accident scenarios caused by completeness uncertainty have been discussed extensively in the risk analysis literature. For example, Kaplan and Garrick ${ }^{5}$ proposed a Bayesian framework to consider unforeseen scenarios, in which an artificially constructed scenario called "others" is added in the analysis to reflect the lack of 
completeness. The total risk is calculated based on the law of total probability and can be updated using Bayesian methods when new observation data become available ${ }^{5}$. Kazemi and Mosleh ${ }^{16}$ applied a similar method to investigate the impact of surprising events on credit risks. Jin et al. ${ }^{17}$ identified major contributors to completeness uncertainty and discussed the impact of completeness uncertainty on the reliability assessment of safety instrumented systems. Kukholskyi et al. ${ }^{18}$ proposed to add a "black box" in the risk assessment model that represent model uncertainty. Bjerga et al. ${ }^{19}$ discussed the exact meaning of completeness uncertainty and proposed a practical approach for handling it in risk assessment. They concluded that completeness uncertainty can be treated as model uncertainty. Most of these works, however, are conceptual: operational guidelines to support their practical implementation are not provided.

\subsection{Model structural uncertainty}

Model structural uncertainty (also referred to as model uncertainty in some papers) arises from the way the PRA model accounts for the features of the processes involved ${ }^{8}$. Because of model structural uncertainty, systematic errors might be introduced into the predicted risk indexes ${ }^{14}$. For example, static PRA models like event tree fail to capture risk indexes that are time-dependent due to various degradation mechanisms ${ }^{20}$.

Mosleh and Droguett reviewed the common approaches used for characterizing model structural uncertainty ${ }^{21}$, ${ }^{22}$. Among them, the alternate hypotheses approach and the adjustment factor approach are listed as two most widely applied ones ${ }^{23}$. The alternate hypotheses approach develops an overall PRA model by probabilistically combining several alternate models, each of which is developed under alternate assumptions of the model structures ${ }^{24}$. The probabilistic combination is done by Bayesian model averaging, where the weights of the alternate models are determined from experimental data or expert judgements that measure closeness of the models to reality ${ }^{25}$. An early application of the alternate hypotheses approach can be found in Apostokakis ${ }^{13}$. Figini and Giudici ${ }^{26}$ applied the alternate hypotheses approach to characterize credit risks when several competing models exist. In Huo et al. ${ }^{27}$, an approach similar to the alternative assumption is used for comparative risk assessment for fossil energy chains considering model uncertainty from the difference in the data sources. Wang et al. ${ }^{28}$ used Bayesian model averaging to tackle the model uncertainty issues arisen in wind power forecasting. A potential limitation of the alternate hypotheses approach is that it requires enumerating a set of mutually exclusive and collectively exhaustive PRA models, which is not always possible in practice ${ }^{21}$.

In the adjustment factor approach, an adjustment factor is added to or multiplied by the prediction result of a reference PRA model to describe the influence of model structural uncertainty ${ }^{29}$. Mosleh and Apostolakis ${ }^{30}$ applied 
the adjustment factor approach to evaluate the influence of model uncertainty on a seismic risk assessment based on experts' judgements. Zio and Apostolakis ${ }^{23}$ used a similar approach for risk assessment of radioactive waste repositories. Park and Grandhi ${ }^{31}$ combined the adjustment factor approach with the alternate hypotheses approach: the adjustment factor approach was used to evaluate the influence of model uncertainty on each alternative model; the adjustment factors were, then, averaged using the alternate hypotheses approach. Ahmadisharaf and Benha ${ }^{32}$ applied the adjustment factor approach to handle the model uncertainty in a risk-based decision making framework for pollutant reductions.

\subsection{Parametric uncertainty}

Parametric uncertainty relates to the estimated values of parameters of the PRA model ${ }^{8}$. Usually, it results in a "level-two" uncertainty analysis setting where outer loop simulations sample realizations of variables subject to epistemic uncertainty (denoted by $E$ ), while for each outer loop simulation, inner loop simulations are conducted to sample from the variables subject to aleatory uncertainty, conditioned on the realizations of $E$ (see ${ }^{33}$ for details). Various mathematical frameworks have been developed for quantifying and propagating parametric uncertainty, e.g., probability theory, evidence theory, possibility theory, probability box, and interval analysis ${ }^{34}$.

In probability-based methods, parametric uncertainty is quantified by probability distributions and the risk index is typically calculated through a double-loop Monte Carlo simulation ${ }^{34}$. Helton et al. ${ }^{34}$ summarized the theoretical basis and implementation procedures of using probability theory to quantify parametric uncertainty. Hao et al. ${ }^{35}$ applied the probability-based framework to consider the parametric uncertainty in a risk assessment of a water inrush accident in a karst tunnel. Flage et al. ${ }^{36}$ compared probability-based methods with probability box-based methods through a production assurance example.

In evidence theory-based methods, parametric uncertainty is described by assigning belief masses to a list of focal sets (e.g., a set of intervals of possible parameter values). The parametric uncertainty is propagated by calculating the plausibility and belief measures for the risk index, which comprise an interval that bounds the probabilistic risk index ${ }^{37}$. For example, Xie et al. ${ }^{38}$ used evidence theory to describe the parametric uncertainty in a PRA model of a pressure vessel subject to corrosion and developed a kriging model-based adaptive sampling method for effective risk assessment.

In possibility theory-based methods, parametric uncertainty is represented by assigning a possibility distribution that quantifies the degree of possibility that each value is actually taken by the uncertain parameter ${ }^{33}$. The parametric uncertainty is, then, propagated based on Zadeh's extension principle to calculate the possibility and necessity 
measures, which are supposed to bound the probabilistic risk index ${ }^{37}$. Toscani et al. ${ }^{39}$ applied a possibility theorybased method to consider the parametric uncertainty in a PRA model for the risk of interference between power and signal lines onboard a satellite. In Dutta ${ }^{40}$, possibility theory was combined with probability distributions for human health risk assessments.

In probability box-based methods, parametric uncertainty is represented by probability boxes, which comprise of an upper and a lower bound for probability distributions. The probability box bounds what would have been the probability distributions for the unknown parameters had the assessor been able to assess these ${ }^{37}$. For example, Zhang et al. ${ }^{41}$ applied the probability box-based method to consider the parametric uncertainty in PRA models of dependent failure processes. Liu et al. ${ }^{42}$ developed an efficient uncertainty propagation method for parameterized probability box based on sparse-decomposition-based polynomial chaos expansion.

In interval analysis-based methods, parametric uncertainty is represented by defining an interval that covers all possible values of the unknown parameter. The uncertainty is, then, propagated by solving an optimization problem to determine the upper and lower bounds for the risk index ${ }^{37}$. Wang et al. ${ }^{43}$ applied interval analysis-based methods to quantify parametric uncertainty in a linkage mechanism model. Chen et al. ${ }^{44}$ used interval analysis-based methods to describe the uncertainty in a composite laminated structure model and developed a reliability-based optimal design method considering the parametric uncertainty.

As shown in the reviews above, most existing methods for EU quantification in PRA only apply to a specific type of EU (either completeness uncertainty, model structural uncertainty or parametric uncertainty). In this paper, we develop a unified framework that is capable to consider the three sources of EU collectively, based on a maturity model for EU management in a PRA.

\section{Maturity model for epistemic uncertainty management}

Various types of EU might affect the PRA model building process (Figure 3). If not properly managed, the EU could impact the results of the PRA and the decisions made based on these results. For example, the first steps of a PRA lead to identifying scenarios that need to be analyzed. Insufficient/incomplete knowledge in these steps would lead to completeness uncertainty. Therefore, the resulting PRA model would not cover all possible scenarios and possibly underestimate the risk. Once the scenarios are identified, models of the evolution of the scenarios are built to compute the risk index for different possible consequences. Model structural uncertainty might be introduced in this part: the model might not fully describe the real physical process, and, as a result, systematic errors in the risk indexes might occur. Finally, in the calculation, parametric uncertainty related to the estimation of the model 
parameters, might lead to inaccurate risk index values and, as a result, affect the decisions made based on these.

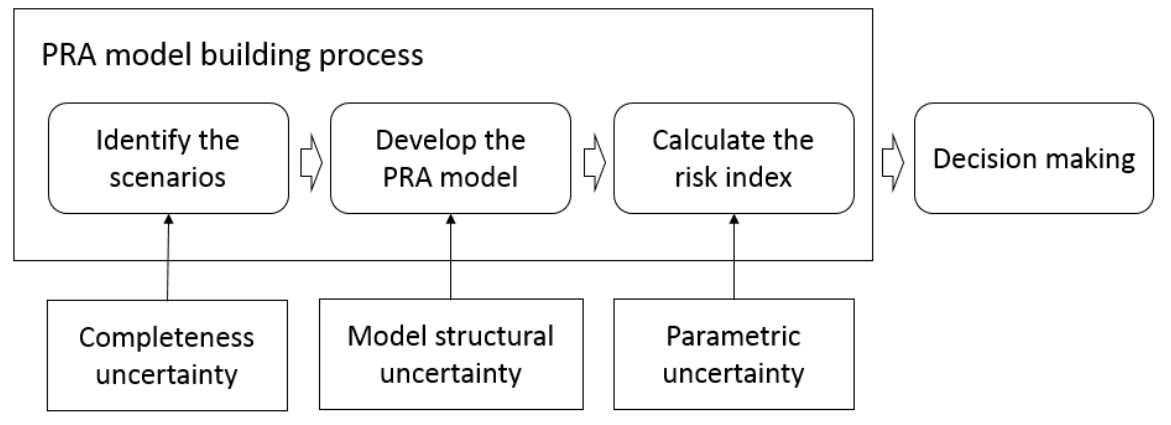

Figure 3 The EU that affects a PRA.

For properly informed decision making, the EU in the PRA needs to be managed. In this paper, we define Epistemic Uncertainty Management (EUM) capability as the ability to identify, characterize and control the epistemic uncertainty in a PRA model. Here, we use the term "epistemic uncertainty" in a broad sense, i.e., it covers completeness uncertainty, model structural uncertainty and parametric uncertainty. EUM must allow evaluating the EU in the PRA model and for this a maturity model for EUM (MM-EUM) is developed in this paper.

Similar to the work on the capability maturity model for software development processes ${ }^{45}$, MM-EUM is a framework to capture the key elements which enable EUM in PRA. The MM-EUM represents an evolutionary improvement from ad hoc EU management to strengthened EU management capability in PRA. This is expected to yield more transparent and trustworthy PRA results, and better support for risk-informed decision making.

The structure of the MM-EUM comprises three elements (Figure 4): maturity levels, activities and goals. Five maturity levels are defined to describe different degrees of EUM in PRA. The five levels are distinguished based on the severity of the potential impact of the EU on the PRA results. A detailed definition of the maturity levels can be found in Sect. 3.1. For each maturity level, several activities that help to generate the corresponding level of maturity are identified (Sect. 3.2). Each activity is associated with one or several goals. If all of the goals at a given maturity level are fulfilled, the PRA reaches such maturity level.

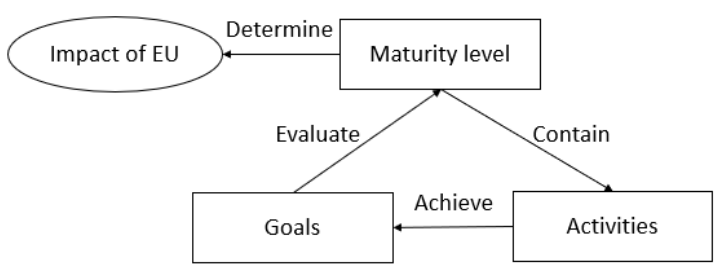

Figure 4 The structure of MM-EUM.

\subsection{Maturity levels}

Let $M_{E U M}$ denote the maturity of EUM for a PRA. Based on the severity of the influence of EU on the PRA 
results, we define five levels of $M_{E U M}$ :

- Initial $\left(M_{E U M}=1\right)$ : The PRA is conducted without considering the influence of EU. The sources of EU and their influence on the result of the PRA are unknown and unmanaged.

- Uncontrolled $\left(M_{E U M}=2\right)$ : The PRA is conducted with an epistemic uncertainty analysis (covering completeness, model structural and parametric uncertainty). The potential impact of EU is known to the decision maker, but no measures have been taken to reduce it.

- Complete $\left(M_{E U M}=3\right)$ : Effective measures have been taken to control the completeness uncertainty (reduce its impact to a desired level). As a result, the PRA is complete: the critical risk contributors that might severely affect the results of the PRA have all been considered in the analysis, given the current knowledge and the degree of accuracy required.

- Adequate $\left(M_{E U M}=4\right)$ : Effective measures have been taken to control the model structural uncertainty. As a result, the developed PRA model is capable to adequately capture the characteristics of the process involved in the risk assessment, given the current knowledge and the degree of accuracy required.

- Accurate $\left(M_{E U M}=5\right)$ : Effective measures have been taken to control the parametric uncertainty. As a result, the parameters in the risk assessment model are estimated to the required level of accuracy.

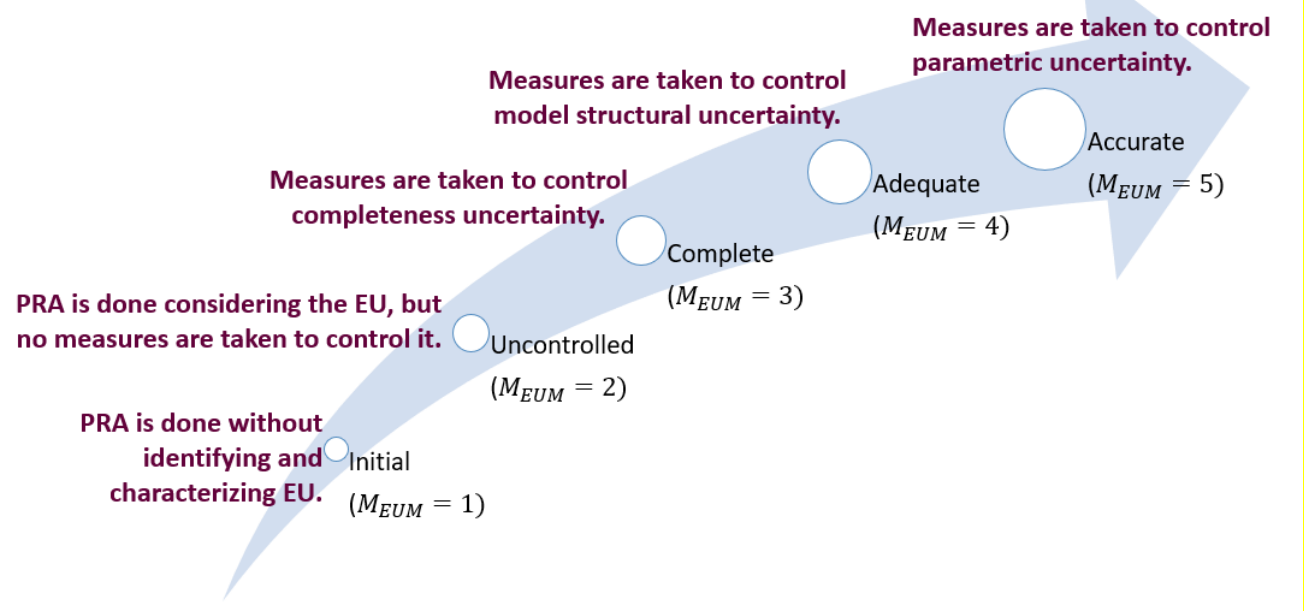

Figure 5 Continuous improvement process of the maturity levels.

As shown in Figure 5, the five maturity levels defined above characterize a cumulative improvement process of the EUM in PRA. The improvement process starts from the Initial level $\left(M_{E U M}=1\right)$. At this level, no analysis has been conducted to identify the possible sources of EU in the PRA. The PRA is conducted without considering the possible influence of EU. 
At the Uncontrolled level $\left(M_{E U M}=2\right)$, the sources of EU in the PRA process have been identified. Through the analysis, the impact of completeness uncertainty, model structural uncertainty and parametric uncertainty are known and quantified. EU has been characterized and propagated into the PRA result using proper mathematical theories. However, the EU is not controlled: no measures are implemented to contain and reduce the existing EU.

At the Complete level $\left(M_{E U M}=3\right)$, not only the achievements of the Uncontrolled level are obtained, the completeness uncertainty is actively controlled as well, through the activities defined in Sect. 3.2. Reaching this level indicates that the EU management is capable to control the completeness uncertainty, so that all the important risk contributors have been considered in the PRA model (to the current knowledge level).

At the Adequate level $\left(M_{E U M}=4\right)$, besides the achievements of the previous levels, the model structural uncertainty is actively controlled through the activities defined in Sect. 3.2. Arriving at this level means that the PRA model is adequate in terms of its capability to account for the actual physical processes involved. Therefore, no significant systematic errors are expected to exist in the results of the PRA.

At the Accurate level $\left(M_{E U M}=5\right)$, in addition to the achievements of the previous levels, the parametric uncertainty is controlled through the activities defined in Sect. 3.2. If a PRA reaches the Accurate level, the EU is properly controlled and one can be confident that the calculated risk index reflects all the available knowledge on the risk as well as the uncertainties.

In our framework, the Uncontrolled level already requires that a "complete" epistemic uncertainty analysis is done, considering completeness, model structural and parametric uncertainties. The difference between the Uncontrolled level and subsequent three levels is that, in the Uncontrolled level, the decision maker only knows how uncertain he/she is due to the impact of EU, but does not take any proactive measures; while starting from the Complete level, proactive measures are taken to reduce the impacts of EU. It should be noted that the orderings of the maturity levels are defined based on the severity of the potential impact of EU for a particular maturity level. For example, the Complete level $\left(M_{E U M}=3\right)$ is considered as less mature than the Adequate and Accurate levels, as the potential impact of completeness uncertainty is more severe than that of model and parametric uncertainty: we should make sure first that we are modelling the correct risk contributors, before considering if we had chosen an appropriate model (model uncertainty) for analysis and if the parameter values are accurately estimated (parametric uncertainty). The maturity model defined in Figure 5 also provides also a sequential process to guide the activities of improvement for reducing epistemic uncertainty: the requirements of a lower maturity level should be satisfied first, before 
considering the requirements of a higher maturity level.

\subsection{Activities and their goals}

With the exception of the Initial level, each maturity level can be achieved by effectively implementing several key activities that support it. To verify if the key activities are implemented successfully, several goals are defined for each key activity: if all the goals for the key activities at a given maturity level $i$ are successfully fulfilled, the corresponding maturity level $i$ is reached, i.e., $M_{E U M}=i$. In Table 2-5, we present the activities and their associated goals that support the maturity levels $2-5$, respectively.

Table 2 Key activities and associated goals for the Uncontrolled level $\left(M_{E U M}=2\right)$.

\begin{tabular}{|l|l|}
\hline Key activities & Goals \\
\hline \multirow{3}{*}{ Document the PRA } & $\begin{array}{l}\text { - The PRA needs to be documented in a well-organized report. } \\
\text { - The report should contain the necessary information for identifying sources of } \\
\text { EU, including completeness uncertainty, model structural uncertainty and } \\
\text { parametric uncertainty. }\end{array}$ \\
\hline Identify the sources of EU & $\begin{array}{l}\text { - Potential sources of EU need to be identified through an analysis conducted by } \\
\text { qualified experts. }\end{array}$ \\
& $\begin{array}{l}\text { The analysis needs to cover completeness uncertainty, model structural } \\
\text { uncertainty and parametric uncertainty. }\end{array}$ \\
& $\begin{array}{l}\text { The results of the analysis need to be confirmed by peer reviews from } \\
\text { independent experts. }\end{array}$ \\
\hline Analyze the impacts of EU & $\begin{array}{l}\text { The impact of the EU on the calculated risk indexes needs to be analyzed by } \\
\text { qualified experts. }\end{array}$ \\
& $\begin{array}{l}\text { The analysis should cover completeness uncertainty, model structural } \\
\text { uncertainty and parametric uncertainty. }\end{array}$ \\
Decision making considers both the calculated risk indexes and the EU in the \\
PRA.
\end{tabular}

Table 3 Key activities and goals for the Complete level $\left(M_{E U M}=3\right)$

\begin{tabular}{|c|c|}
\hline Key activities & Goals \\
\hline $\begin{array}{l}\text { Establish knowledge base } \\
\text { to support the risk } \\
\text { assessment model }\end{array}$ & $\begin{array}{l}\text { - The knowledge base needs to be established to support the PRA. } \\
\text { - The knowledge base needs to contain sufficient information from failures in } \\
\text { similar systems/processes. } \\
\text { - The knowledge base needs to be managed by experienced analysts. } \\
\text { - The major steps in the PRA (Figure 3) are all supported by sufficient } \\
\text { knowledge. }\end{array}$ \\
\hline $\begin{array}{l}\text { Review the scope of and } \\
\text { key assumptions made in } \\
\text { the risk assessment model }\end{array}$ & $\begin{array}{l}\text { - The scope of the assessment and the key assumptions need to be clearly stated } \\
\text { in the PRA report. } \\
\text { - The scope and the assumptions need to be reviewed by qualified external } \\
\text { experts. } \\
\text { - A comprehensive methodology is used to identify reference accident scenarios. } \\
\text { - Sources of completeness uncertainty need to be identified based on the review } \\
\text { of the scope and assumptions of the PRA. } \\
\text { - Impacts of completeness uncertainty need to be analyzed by experts. }\end{array}$ \\
\hline $\begin{array}{l}\text { Review the completeness } \\
\text { of the analysis }\end{array}$ & $\begin{array}{l}\text { - An expert review should be conducted on the completeness of the analysis. } \\
\text { - The experts should be experienced and are familiar with the problem of } \\
\text { interests. } \\
\text { - Through the review, the experts identify no risk contributors that are missing in } \\
\text { the analysis or some missing risk contributors are identified, but their impacts } \\
\text { are negligible. }\end{array}$ \\
\hline
\end{tabular}


Table 4 Key activities and goals for the Adequate level $\left(M_{E U M}=4\right)$

\begin{tabular}{|c|c|}
\hline Key activities & Goals \\
\hline $\begin{array}{l}\text { Examine the assumptions } \\
\text { and limitations of the } \\
\text { selected PRA model }\end{array}$ & $\begin{array}{l}\text { - Key assumptions in the selected PRA model need to be clearly described and } \\
\text { documented. } \\
\text { - Applicability and limitations of the selected PRA model need to be clearly } \\
\text { described and documented. }\end{array}$ \\
\hline $\begin{array}{l}\text { Review the adequacy of } \\
\text { the used PSA model }\end{array}$ & $\begin{array}{l}\text { - Key characteristics of the process involved in the risk assessment need to be } \\
\text { identified. } \\
\text { - The PRA model's capability to adequately capture the key characteristics need } \\
\text { to be reviewed by qualified external experts. }\end{array}$ \\
\hline $\begin{array}{l}\text { Validate the model } \\
\text { adequacy }\end{array}$ & $\begin{array}{l}\text { - Tests need to be conducted to validate the adequacy of the model. } \\
\text { - The results of the tests need to confirm the key assumptions regarding the } \\
\text { structure of the PRA model. }\end{array}$ \\
\hline $\begin{array}{l}\text { Verify the quality of the } \\
\text { modelling process } \\
\text { (Verification) }\end{array}$ & $\begin{array}{l}\text { - The quality of the modelling process needs to be verified through a review for } \\
\text { verification and validation }(\mathrm{V} \& \mathrm{~V}) \text { review }{ }^{46} \text {. } \\
\text { Through the review, it is concluded that the selected model is implemented } \\
\text { correctly, so that the developed PRA model accurately represents the } \\
\text { conceptual model for the physical process of interests understood by the } \\
\text { modeler. }\end{array}$ \\
\hline $\begin{array}{l}\text { Control the impact of } \\
\text { model structural } \\
\text { uncertainty }\end{array}$ & $\begin{array}{l}\text { - A clear target is set up for the acceptable level of model structural uncertainty, } \\
\text { based on the requirements of decision making. } \\
\text { - The choice of the PRA model is modified, if suggested by the review and/or } \\
\text { the validation tests, to make sure that the selected PRA model is capable of } \\
\text { modeling the associated characteristics of the risk processes. } \\
\text { - The model structural uncertainty in the PRA is properly controlled to be } \\
\text { within the acceptable limit and verified by experts through peer reviews and } \\
\text { validation tests. }\end{array}$ \\
\hline
\end{tabular}

Table 5 Key activities and goals for the Accurate level $\left(M_{E U M}=5\right)$

\begin{tabular}{|c|c|}
\hline Key activities & Goals \\
\hline $\begin{array}{l}\text { Collect relevant data for } \\
\text { parameter estimation }\end{array}$ & $\begin{array}{l}\text { - Sufficient amount of data is collected to support model parameter estimation. } \\
\text { - The data are collected from systems/processes similar to the target } \\
\text { systems/processes. }\end{array}$ \\
\hline $\begin{array}{l}\text { Review the accuracy of } \\
\text { the estimated model } \\
\text { parameters }\end{array}$ & $\begin{array}{l}\text { - The quality of the data collection process is reviewed and verified by experts. } \\
\text { - The accuracy of the estimated parameters is reviewed and verified by external } \\
\text { experts. }\end{array}$ \\
\hline $\begin{array}{l}\text { Validate the accuracy of } \\
\text { the PRA model } \\
\text { (Validation) }\end{array}$ & $\begin{array}{l}\text { The accuracy of the PRA model needs to be validated through a verification } \\
\text { and validation }(\mathrm{V} \& \mathrm{~V}) \text { review }{ }^{46} \text {. } \\
\text { - Through the review and validation experiments, the degree of accuracy of the } \\
\text { PRA model is considered to be sufficient to support the required decision } \\
\text { making. }\end{array}$ \\
\hline Sensitivity analysis & $\begin{array}{l}\text { - The impact of parametric uncertainty is determined by conducting sensitivity } \\
\text { analysis, considering the accuracy of the estimated parameters. }\end{array}$ \\
\hline $\begin{array}{l}\text { Control the impact of } \\
\text { parametric uncertainty }\end{array}$ & $\begin{array}{l}\text { - A clear target is set up for the acceptable level of parametric uncertainty, } \\
\text { based on the requirements of decision making. } \\
\text { - The data collection and parameter estimation processes are enhanced until the } \\
\text { accuracy can be confirmed by the review. } \\
\text { - The parametric uncertainty in the PRA is properly controlled to be within the } \\
\text { acceptable limit and verified by experts through peer reviews. }\end{array}$ \\
\hline
\end{tabular}


The activities and goals defined in Table 2-5 can be used to evaluate the maturity level in EUM:

- if all the goals of the activities for a given maturity level $i$ are fulfilled, the corresponding maturity level is considered as being reached, i.e., $M_{E U M}=i$;

- $\quad$ otherwise, we have $i-1<M_{E U M}<i$. The precise value is determined by experts based on the degree to which the goals are satisfied.

Besides, the activities and goals can also be used to plan the efforts needed to control the EU in the PRA. Suppose that the current maturity level is $i$ : To improve the EUM capability of the PRA, one needs to focus on the activities and unsatisfied goals at maturity level $i+1$.

A similar maturity model has been developed by Oberkampf et al. ${ }^{47}$ to evaluate the predictive capability maturity of computational modelling and simulations. The difference between the developed model and the one in Oberkampf et al. ${ }^{47}$ is that the developed model focuses on the entire risk analysis process, including identifying hazard sources, risk modelling, risk calculation, etc. The model in Oberkampf et al. ${ }^{47}$, on the other hand, is specially designed for modelling and simulation. The concept of predictive capability maturity, however, can be used as a way to evaluate the EUM, especially with respect to the management of model structural and parametric uncertainty.

\section{An integrated risk index for considering epistemic uncertainty}

Through the model defined in Sect. 3, the severity of the influence of epistemic uncertainty on the result of PRA can be quantified in terms of $M_{E U M}$. In this section, we develop a new risk index that allows integrating the result of the PRA with the epistemic uncertainty for a more complete risk characterization. More specifically, consider the following illustrative example: suppose that a PRA based on event tree analysis predicts that the risk of a given consequence is Risk $_{P}^{*}=10^{-3}$. Further, let us assume that based on the MM-EUM defined in Sect. 3, the EUM of the PRA is assessed to be $M_{E U M}=3$. Then, in this section, we focus on the following question: how does the information on epistemic uncertainty impacts our beliefs on the predicted risk values?

To address this issue, an uncertainty equivalence model is developed first in Sect. 4.1 for integrating the prediction result of the PRA model with the epistemic uncertainty. Then, the new risk index, called belief risk index, is defined in Sect. 4.2. Finally, an indifference method is presented in Sect. 4.3 to determine the contribution of epistemic uncertainty based on the evaluated EUM for practical belief risk index evaluation.

\subsection{Uncertainty equivalence model}

Let us consider a generic PRA model: 


$$
\operatorname{Risk}_{P}^{*}=f\left(\boldsymbol{\theta}^{*}\right) .
$$

In Eq. (1), Risk ${ }_{P}^{*}$ is the estimated probabilistic risk index (* indicates estimates); $f(\cdot)$ denotes the PRA model used for calculating $\operatorname{Risk}_{P}^{*}$ (e.g., fault trees, event trees); $\boldsymbol{\theta}^{*}$ is a vector containing the estimated values of the model parameters. Risk $k_{P}^{*}$ is an estimate of the true (but unknown) frequency of the given consequence, based on the model $f(\cdot)$ and the estimates $\boldsymbol{\theta}^{*}$ of the true (but unknown) values of the model parameters. For example, in the aforementioned illustrative example, Risk $k_{P}^{*}$ is estimated based on the event tree model to be $10^{-3}$. This value of $\operatorname{Risk}_{P}^{*}$, however, does not consider the potential influence of epistemic uncertainty on the PRA.

An uncertainty equivalence model is developed to integrate the epistemic uncertainty in the PRA with the (aleatory) uncertainty in the model prediction ( $\operatorname{Risk}_{P}^{*}$ ). For this, let us first artificially construct a PRA model for the same consequence of Eq. (1), where the safety margin of the corresponding consequence is $S_{E}$, i.e., the consequence occurs whenever $S_{E}<0$. Let us further assume that:

Assumption 1. The safety margin $S_{E}$ follows a normal distribution $S_{E} \sim \operatorname{Normal}\left(\mu_{S_{E}}, \sigma_{S_{E}}^{2}\right)$ and

$$
\frac{\mu_{S_{E}}}{\sigma_{S_{E}}}=-\Phi^{-1}\left(\text { Risk }_{P}^{*}\right)
$$

where Risk $_{P}^{*}$ is calculated by the PRA model in Eq. (1) and $\Phi^{-1}(\cdot)$ is the inverse cumulative distribution function of a standard normal distribution.

From Eq. (2), it is easy to verify that

$$
\operatorname{Pr}\left(S_{E}<0\right)=\Phi\left(-\frac{\mu_{S_{E}}}{\sigma_{S_{E}}}\right)=\operatorname{Risk}_{P}^{*},
$$

where $\Phi(\cdot)$ is the cumulative distribution function (CDF) of a standard normal distribution. Hence, the uncertainty in the predicted risk index $\operatorname{Risk}_{P}^{*}$ is equivalent to the artificially constructed PRA model with a safety margin $S_{E}$ 48. Therefore, the auxiliary random variable $S_{E}$ is called equivalent safety margin.

Please note that the purpose of making Assumption 1 is to artificially construct a PRA with equivalent uncertainty as the original PRA model in Eq. (1). For this, the equivalent safety margin $S_{E}$ only needs to satisfy $\operatorname{Pr}\left(S_{E}<0\right)=$ Risk $^{*}$ : that is, any random variable that satisfies $\operatorname{Pr}\left(S_{E}<0\right)=$ Risk $^{*}$ can be selected as the equivalent safety margin. However, to integrate epistemic uncertainty in the developed model, one also needs to identify the 
distribution of the equivalent safety margin. The selected distribution should reflect the decision makers' prior belief on how the safety margin is distributed and will be updated by integrating epistemic uncertainty. In practice, the distribution of the equivalent safety margin can be determined through expert elicitation ${ }^{49}$. In Assumption 1, for simplicity and illustrative purposes, we directly assume that the equivalent safety margin follows a normal distribution. The developed methods, however, can be naturally extended to other distributions.

It should also be noted that even though we adopt Assumption 1, there are still infinite choices of $\mu_{S_{E}}, \sigma_{S_{E}}$, as long as Eq. (2) holds. In practice, we can fix one of the two parameters and calculate the other one from Eq. (2). It can be seen in Sect. 4.2 that the values of $\mu_{S_{E}}, \sigma_{S_{E}}$ do not affect the value of the belief risk index, provided that their values satisfy Eq. (2). For example, in the illustrative example of event tree models, as $R_{i s k_{P}^{*}}^{*} 10^{-3}$, if we set $\sigma_{S_{E}}=1$, then, from Eq. (2), $\mu_{S_{E}}=-1 \cdot \Phi^{-1}\left(\operatorname{Risk}_{P}^{*}\right) \cdot \sigma_{S_{\mathrm{E}}}=3.0902$. Hence, the uncertainty in the result of the event tree analysis can be viewed as equivalent to an artificially constructed PRA, where the equivalent safety margin is $S_{E} \sim \operatorname{Normal}(3.0902,1)$.

To integrate EU in the uncertainty equivalence model, we make the following assumption:

Assumption $2{ }^{14}$. EU increases the dispersion of the distribution of the equivalent safety margin but does not affect its center.

Assumption 2 is about how a decision maker evaluates the effect of epistemic uncertainty. Hence, it is a subjective distribution that reflects personal belief, rather than an objective probability distribution that is supposed to replicate reality. Therefore, we might not have a definite "correct" choice: the decision maker can choose different assumptions, which will result in different belief risk indexes. In this paper, we made this assumption primarily due to the convenience it will bring to the model development. However, the assumption itself is not baseless. In fact, it is in line with the addictive error model commonly used in the adjustment factor approach (see Sect. 2.3 of ${ }^{30}$ ).

A graphical illustration of Assumption 2 is given in Figure 6. Therefore, the effect of EU (including completeness uncertainty, model structural uncertainty and parametric uncertainty) can be modeled by replacing the equivalent safety margin with the EU-affected equivalent safety margin $S_{E}^{\prime}$ :

$$
S_{E}^{\prime}=S_{E}+\epsilon_{e}
$$

where $\epsilon_{e}$ is the adjustment factor for $\mathrm{EU}$ and is assumed to be

$$
\epsilon_{e} \sim \operatorname{Normal}\left(0, \sigma_{e}^{2}\right)
$$

Eq. (4) shows that by making Assumptions 1 and 2, the overall uncertainty (including the uncertainty in Risk $k_{P}^{*}$ and the EU) in the PRA is equivalent to that of presumed PRA with a safety margin $S_{E}^{\prime}$. Hence, the model in Eq. (4) 
is called uncertainty equivalence model. The parameter $\sigma_{e}$ controls how much EU affects the results of the PRA and is assumed to be proportional to the mean $\mu_{S_{E}}$ :

$$
\sigma_{e}=\alpha_{e} \cdot \mu_{S_{E}}
$$

As in Assumption 2, the assumption we made in Eq. (6) is also a subjective reflection of decision makers' attitude towards epistemic uncertainty. Other assumptions might also be adopted, which will lead to different definitions of the belief risk indexes. The assumption we made in Eq. (6) is similar to that in the multiplicative error model (see Sect. 2.4 of $^{30}$ ). The parameter $\alpha_{e}$ characterizes the magnitude of the effect of EU on the PRA model results and is called Epistemic Uncertainty Factor (EUF). The EUF takes values in $[0, \infty)$, where a large value indicates a large effect of EU. The meaning of the EUF parameter is the additional dispersion brought by EU on the equivalent safety margin. The value of $\alpha_{e}$ is determined based on the maturity for EUM, as explained in the next Sect. 4.3. We stress that both $S_{E}$ and $S_{E}^{\prime}$ reflect the analysts' belief on how likely the given consequence will occur, based on the results of the PRA. Using $S_{E}$ indicates that the EU is not considered; using $S_{E}^{\prime}$ amounts to considering also the EU that affects the PRA model results (by the EUF). For example, in the aforementioned illustrative example, we have $S_{E} \sim \operatorname{Normal}(3.0902,1)$. To consider the effect of EU, let us assume, based on the fact that $M_{E U M}=3$, that the EUF of the PRA is $\alpha_{e}=0.5$ (in Sect. 4.3, we elaborate on how to obtain this value based on $M_{E U M}$ ). Then, from Eqs. (4)-(6), $S_{E}^{\prime} \sim \operatorname{Normal}(3.0902,3.3873)$. It can be seen that the dispersion of the believed safety margin distribution increases significantly, due to the effect of EU.

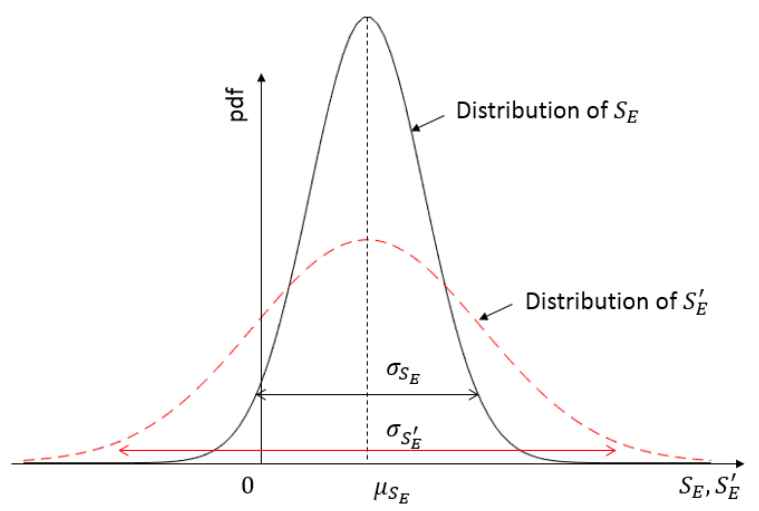

Figure 6 Effect of EU on the PRA results seen in terms of $S_{E}$.

\subsection{Definition of belief risk index}

A new risk index, called belief risk index ( $\operatorname{Risk}_{B}$ ), is, then, defined based on Eq. (4), to consider the effect of 
EU on PRA:

$$
\operatorname{Risk}_{B} \triangleq \operatorname{Pr}\left(S_{E}^{\prime}<0\right)=\Phi\left(-\frac{\mu_{S_{E}}}{\sqrt{\sigma_{S_{E}}^{2}+\sigma_{e}^{2}}}\right)
$$

It can be seen from Eq. (7) that the belief risk index is the probability that the (EU) affected safety margin is less than zero. The concept of safety margin has been widely used in structural reliability analysis ${ }^{50}$. It can be seen that when there is no epistemic uncertainty and the safety margin follows a normal distribution, the belief risk index as defined in Eq. (7) is equivalent to the structural unreliability. The major difference between our developed metric in Eq. (7) and the traditional structural reliability theory is that, Eq. (7) allows explicitly considering epistemic uncertainty, which is not considered in the structural reliability theory. The belief risk index is defined with respect to a specific consequence and measures the uncertainty on the occurrence of this consequence. It should be noted that the probability here takes the subjective interpretation: it measures the belief degree on the occurrence of a given consequence, based on both the prediction of the PRA model and the EU that affects the PRA model. From Eq. (7), we can see that the uncertainty in $\operatorname{Risk}_{B}$ is equivalent to that of a PRA model result where the safety margin is $S_{E}^{\prime} \sim \operatorname{Normal}\left(\mu_{S_{E}}, \sigma_{S_{E}}^{2}+\sigma_{e}^{2}\right)$. For example, in the aforementioned illustrative example, as we have $S_{E}^{\prime} \sim \operatorname{Normal}(3.0902,3.3873)$, it is easy to calculate from Eq. (7) that Risk $k_{B}=0.0466$. This value can be interpreted as follows: given the PRA model prediction and the EU in the model, it is believed that the uncertainty on the occurrence of a given consequence is equivalent to the results of an artificially constructed PRA, where the probabilistic risk index is 0.0466 . This, however, does not mean that the belief risk index can be interpreted based on the frequentist interpretation of probability. Rather, the belief risk index is a subjective metric that allows comparing the decision makers' personal belief degree on the uncertainty in the PRA results. It should be noted that sometimes the order relationships indicated by the belief risk indexes is more interesting to the decision makers than the absolute values. For example, suppose that we have two cases where $\operatorname{Risk}_{B, 1}=0.0466$ and $\operatorname{Risk}_{B, 2}=0.0105:$ a proper interpretation is that we are more confident (less uncertain) in the second case that the predicted consequence by the PRA model will not occur.

Eq. (7) is not very easy to use in practice, as one usually only knows the value of Risk ${ }_{P}^{*}$ (calculated from the PRA model), not $\mu_{S_{E}}$ and $\sigma_{S_{E}}$. Substituting Eqs. (2) and (6) into Eq. (7), we have 


$$
\operatorname{Risk}_{B}=\Phi\left(\frac{\Phi^{-1}\left(\operatorname{Risk}_{P}^{*}\right)}{\sqrt{1+\left(\alpha_{e} \cdot \Phi^{-1}\left(\operatorname{Risk}_{P}^{*}\right)\right)^{2}}}\right) \text {. }
$$

Eq. (8) can be used for practical evaluation of the belief reliability index, as shown in the next Sect. 5.

The effect of EU on the belief risk index can be investigated graphically. First note that both $S_{E}$ and $S_{E}^{\prime}$ have been assumed to follow normal distributions. Therefore, they can be transformed into the standard normal space by taking the transformation:

$$
Z=\frac{X-\mu_{X}}{\sigma_{X}},
$$

where $X=S_{E}, S_{E}^{\prime}$, respectively.

It is easy to verify that in the standard normal space, the distance from the origin to the failure region associated with $S_{E}$ is ${ }^{50}$

$$
d_{P}=\left|\Phi^{-1}\left(\operatorname{Risk}_{P}^{*}\right)\right|=\left|\frac{\mu_{S_{E}}}{\sigma_{S_{E}}}\right|,
$$

while after considering the EU, the distance becomes

$$
d_{B}=\left|\Phi^{-1}\left(\operatorname{Risk}_{B}\right)\right|=\left|\frac{\Phi^{-1}\left(\operatorname{Risk}_{P}^{*}\right)}{\sqrt{1+\alpha_{e}^{2} \cdot\left(\Phi^{-1}\left(\operatorname{Risk}_{P}^{*}\right)\right)^{2}}}\right|=\frac{d_{P}}{\sqrt{1+\alpha_{e}^{2} \cdot d_{P}^{2}}},
$$

as shown in Figure 7. As $\alpha_{e} \geq 0$, we have $d_{B} \leq d_{P}$, which shows that considering EU decreases the safety margin. Therefore, Risk ${ }_{B}$ always provides a more conservative value of the risk index than the probabilistic risk index.

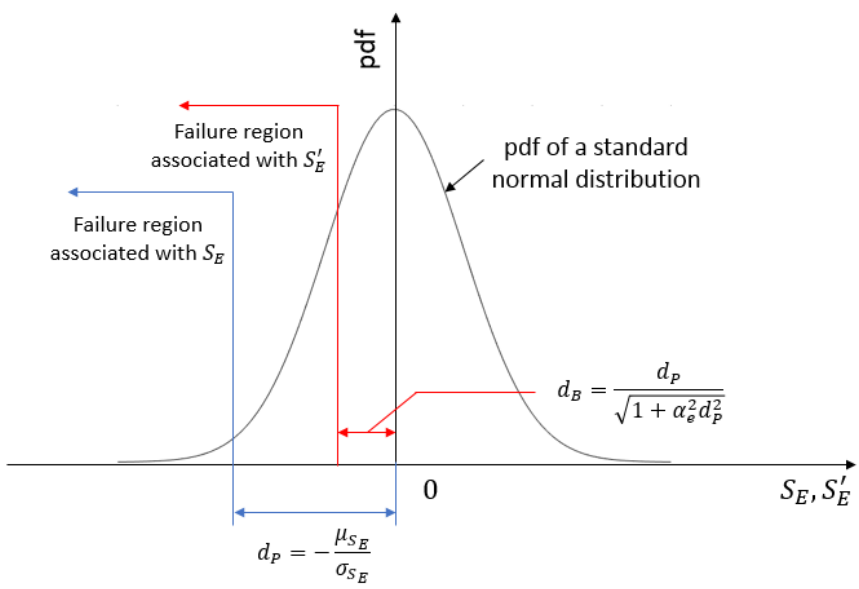


Figure 7 Graphical interpretation of Risk $_{B}$.

Another observation is that when the EU has the most severe influence, we have $\alpha_{e} \rightarrow \infty$ and $R i s k_{B} \rightarrow 0.5$. This indicates that Risk $_{B}=0.5$ is a state of maximal EU: at this state, one is totally ignorant about the system state due to the influence of the EU (we cannot judge whether the consequence is more likely to occur or not to occur). Therefore, Risk $k_{B}$ can be regarded as a measure of confidence on the result of the PRA: the closer Risk $k_{B}$ to 0.5 , the less sure one is about the result of the PRA, and, then, one should not to use the PRA model results for decision making.

\subsection{Indifference method for belief risk index evaluation}

Figure 8 shows the implementational procedures for evaluating the belief risk index in practice. The first step is to calculate the probabilistic risk index $\operatorname{Risk}_{P}^{*}$ through a conventional PRA. Then, the EU is evaluated in terms of the EUF $\alpha_{e}$, based on the maturity of EUM in the PRA. Finally, the value of Risk $k_{B}$ can be calculated using Eq. (8).

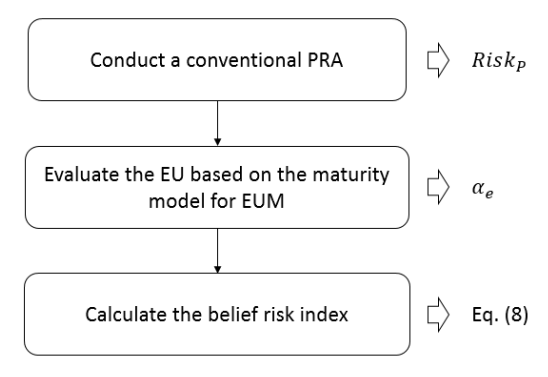

Figure 8 Structure of the procedures for evaluating $\operatorname{Risk}_{B}$.

A critical step in Figure 8 is to determine the value of $\alpha_{e}$. For this, the $M_{E U M}$ of the PRA is evaluated first, following the guidelines in Sect. 3.2. The value of $M_{E U M}$ relates to the level of EU, where $M_{E U M}=1$ means that the impact of EU is the greatest whereas $M_{E U M}=5$ indicates the lowest impact. Obviously, $\alpha_{e}$ is a decreasing function of $M_{E U M}$ :

$$
\alpha_{e}=h\left(M_{E U M}\right) .
$$

The function $h(\cdot)$ reflects the tolerance on the EU. This can be shown by investigating the dependence of Risk $_{B}$ on $M_{E U M}$, when the PRA model predicts that $\operatorname{Risk}_{P}^{*}=0$, as shown in Figure 9. Once $h(\cdot)$ is known, Figure 9 can be drawn by substituting Eq. (12) into Eq. (8) and letting $\operatorname{Risk}_{P}^{*} \rightarrow 0$ : 


$$
\begin{aligned}
\operatorname{Risk}_{B} \mid \operatorname{Risk}_{P}^{*} \rightarrow 0 & =\Phi\left(\frac{\Phi^{-1}\left(\text { Risk }_{P}^{*}\right)}{\sqrt{1+\alpha_{e}^{2} \cdot\left(\Phi^{-1}\left(\operatorname{Risk}_{P}^{*}\right)\right)^{2}}}\right)=\Phi\left(-\frac{1}{\sqrt{\left(\frac{1}{\Phi^{-1}\left(\text { Risk }_{P}^{*}\right)}\right)^{2}+\alpha_{e}^{2}}}\right) \\
& =\Phi\left(-\frac{1}{\alpha_{e}}\right)=\Phi\left(-\frac{1}{h\left(M_{E U M}\right)}\right) .
\end{aligned}
$$

Typically, the attitude towards EU exhibits three types of behaviors, i.e., EU-averse, EU-neutral and EU-prone, as shown in Figure 9:

- for EU-prone, Risk $\mid$ Risk $_{P}^{*} \rightarrow 0$ is a convex function of $M_{E U M}$, meaning that even though the EU is quite large ( $M_{E U M}$ is relatively immature), there is willingness to trust the prediction of the PRA model;

- for EU-averse, Risk ${ }_{B} \mid \operatorname{Risk}_{P}^{*} \rightarrow 0$ is a concave function of $M_{E U M}$, meaning that only when the EU is very small ( $M_{E U M}$ is highly mature), there is willingness to trust the prediction of the PRA model;

- EU-neutral lies between the two extremes: $\operatorname{Risk}_{B} \mid$ Risk $_{P}^{*} \rightarrow 0$ is approximately a linear function of $M_{E U M}$.

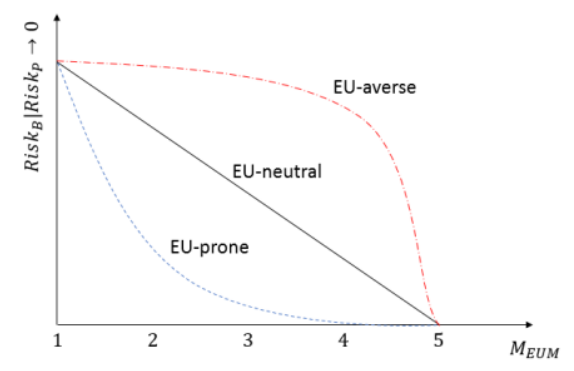

Figure 9 Typical behaviors of Risk $_{B} \mid$ Risk $_{P}^{*} \rightarrow 0$ under different values of $M_{E U M}$.

In this paper, we suggest the following form of $h(\cdot)$, for its flexibility to model EU-averse, EU-prone, and EU-neutral attitudes:

$$
\alpha_{e}=h\left(M_{E U M}\right)=K\left(\frac{1}{M_{E U M}-1}-\frac{1}{4}\right)
$$

where $K$ is a parameter that determines the attitude towards EU, as shown in Figure 10. 


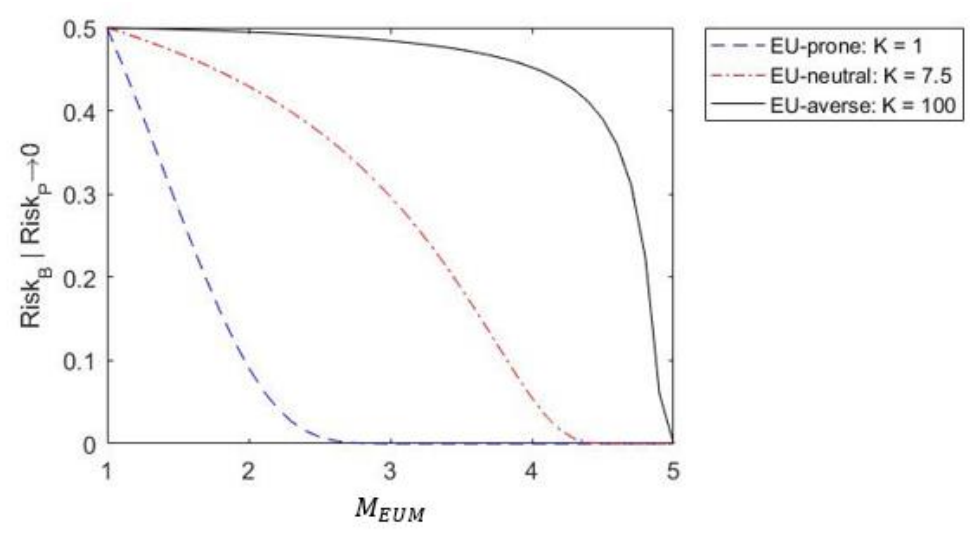

Figure 10 Attitude towards EU at different values of $K$.

The values of $K$ can be estimated using an indifference method. A survey is first conducted to collect empirical data from the decision makers. The decision makers are asked to participate the following thought experiment: Suppose you are concerned with a given consequence of an accident, which, if it occurs, brings you a financial loss of one Yuan (Chinese currency). An insurance company offers you an insurance plan: if the accident actually occurs, you will get a reimbursement of one Yuan. Suppose that you conduct a PRA, which shows that Risk ${ }_{P}^{*}=0$, i.e., there is no risk on this specific consequence at all. Suppose we have five cases, where the $M_{E U M}$ for the PRA process is Unmanaged $\left(M_{E U M}=1\right)$, Uncontrolled $\left(M_{E U M}=2\right)$, Complete $\left(M_{E U M}=3\right)$, Adequate $\left(M_{E U M}=4\right)$ and Accurate ( $\left.M_{E U M}=5\right)$, respectively. Then, for the five cases, what are the highest prices that make you willing to buy the insurance, respectively?

Denote the answers from the decision makers by $\beta_{1}, \beta_{2}, \cdots, \beta_{5}$, respectively. These values, then, reflect the decision makers' beliefs on the values of $\operatorname{Risk}_{B} \mid \operatorname{Risk}_{P}^{*} \rightarrow 0$ under different levels of $M_{E U M}$. Therefore, they can be used as empirical data for estimating the parameter $K$. Note that we have $\beta_{1}=0.5$, as $M_{E U M}=1$ is the state with maximal EU and, therefore, corresponds to $R_{B}=0.5$, as shown in Sect. 4.1. Similarly, we have $\beta_{5}=0$, as $M_{E U M}=5$ is the state with no EU, when we trust the prediction of the PRA model. Therefore, the decision makers only need to assign values to $\beta_{2}, \beta_{3}$ and $\beta_{4}$.

In this paper, we use the least square method for parameter estimation, in which the value of $K$ is found by solving the following minimization problem: 


$$
\min _{K} S S E=\sum_{i=1}^{5}\left(\beta_{i}-\Phi\left(-\frac{1}{K\left(\frac{1}{M_{E U M}-1}-\frac{1}{4}\right)}\right)\right),
$$

where SSE represents the sum of square error of the data and $\beta_{i}, i=1,2, \cdots, 5$ are empirical data collected from experts based on the thought experiment presented before. The optimization problem can be solved easily using standard nonlinear programming methods, e.g., sequential quadratic programming ${ }^{41}$.

\section{An application}

In this section, we apply the developed methods on a case study of the PRA of an NPP. The application follows the procedures described in Figure 8. The system description is given in Sect. 5.1. The PRA model for the NPP is presented in Sect. 5.2. In Sects. 5.3 and 5.4, the maturity of the EUM in the specific PRA is evaluated and the indifference method is applied for evaluating Risk $_{B}$. The results of this case study are presented in Sect. 5.5, with some discussions.

\subsection{System description}

We consider a PRA of an NPP operated by Electricité De France (EDF) ${ }^{51}$. The objective of the PRA is to evaluate the risk of core meltdown caused by external flooding. External flooding refers to the overflow of water into the NPP due to naturally induced external causes, e.g., tides, tsunamis, snow melts, storm surges, etc ${ }^{51}$. The NPP is designed with various safety barriers to contain the possible event sequences following the occurrence of external flooding, e.g., dams built to block the water from entering the NPP, emergency sewerage system, etc ${ }^{51}$. Depending on the states of these safety barriers, different consequences might be caused by the external flooding. Among them, core meltdown is the most severe one. A PRA is conducted to calculate the probability of having core meltdown caused by external flooding, denoted by $\operatorname{Risk}_{P}^{*}$.

\subsection{PRA model}

The developed PRA model is a combination of event trees and fault trees. Event trees are used to model possible event sequences following the external initiating events, considering different water level conditions (called scenarios) and operation states of the NPP. The risk index Risk $k_{P}^{*}$ is calculated by summing the scenario probabilities for those scenarios which end in a core meltdown event. Fault tree models are constructed to compute the probabilities of failure of the safety barriers from the selected Basic Events (BEs). Eventually, the PRA model can be expressed as a combination of BEs in Minimal Cut Sets (MCSs) such that when all the BEs in the MCSs occur, the consequence of 
core meltdown occurs (Table 6).

It should be noted that in Table 6, we present only one MCS: the real PRA model, however, has a much larger scale, which comprises of several operating states, scenarios, thousands of BEs and MCSs (the exact number cannot be given due to confidentiality reasons). The risk index is calculated considering all the BEs and MCSs (the result has been scaled, again due to confidentiality reasons):

$$
\operatorname{Risk}_{P}^{*}=5.78 \times 10^{-6} \text {. }
$$

Table 6 An example of the PRA model

\begin{tabular}{|c|c|c|c|}
\hline Operating state & Scenario & MCS & $\mathrm{BE}$ \\
\hline \multirow{3}{*}{$\begin{array}{l}\text { Not Success } \\
\text { due to Steam } \\
\text { Generator } \\
\text { (NS/SG) }\end{array}$} & \multirow{3}{*}{$\begin{array}{l}\text { Water } \\
\text { level A }\end{array}$} & \multirow{3}{*}{$\begin{array}{l}M C S_{1} \\
=\left\{B E_{1}, B E_{2}, B E_{3}\right\}\end{array}$} & $\begin{array}{l}B E_{1} \text { : External flooding with water level A inducing a } \\
\text { loss of offsite power }\end{array}$ \\
\hline & & & $\begin{array}{l}B E_{2}: \text { Loss of auxiliary feedwater system due to the } \\
\text { failure to close the isolating valve }\end{array}$ \\
\hline & & & $\begin{array}{l}B E_{3}: \text { Loss of component cooling system because of } \\
\text { clogging }\end{array}$ \\
\hline
\end{tabular}

\section{$5.3 M_{E U M}$ evaluation}

The procedures for the evaluation are summarized in Figure 11. For each maturity level $i, 2 \leq i \leq 5$, the goals defined in Table 2-5 are used to examine if such level of maturity has been reached. The evaluation needs to be done by experts based on a careful review of the PRA. In this case, to facilitate the assessment of the experts, a questionnaire like Table 7 is used. The questionnaire lists the goals corresponding to a given maturity level and asks the expert to evaluate the degree to which each goal is satisfied. Three degrees are considered, i.e., not at all, partly and very well. The experts are asked to mark in the Table the degree which they think best describes the PRA.

In this case study, the PRA is well documented in a detailed risk assessment report ${ }^{51}$. The goals associated with maturity level 2 are examined using the questionnaire in Table 7 based on an expert review of the risk assessment report. Through the review, it is found out that although an analysis of EU has been performed when the PRA was conducted, the analysis only considers the completeness uncertainty: an expert review confirms that the PRA already covers the major risk contributors. Therefore, the potential influence of completeness uncertainty is negligible. The other two sources of EU, i.e., model structural uncertainty and parametric uncertainty, however, were not considered in the EU analysis of the original PRA. Besides, in the original PRA report, decisions are simply made by comparing the calculated Risk $_{P}^{*}$ to an acceptance criterion. The effect of EU was not considered in the decision making process. Based on the above observations, the experts determine the degrees to which the goals of maturity level 2 are satisfied, as shown in Table 7. Then, as shown in Figure 11, since the PRA process of the NPP satisfies four out of 
the eight goals of maturity level 2 , the $M_{E U M}$ for this process should be between levels 1 and 2 . To determine the value, we assume for simplicity that if a goal is satisfied, a contribution of $1 / 8=0.125$ is added to the $M_{E U M}$; if a goal is satisfied partly, a contribution of 0.05 is added to the $M_{E U M}$; if a goal is not satisfied at all, no contribution is made to the $M_{E U M}$. Then, the maturity level is determined to be:

$$
M_{E U M}=1+0.125 \times 4+0.05 \times 2=1.6 .
$$

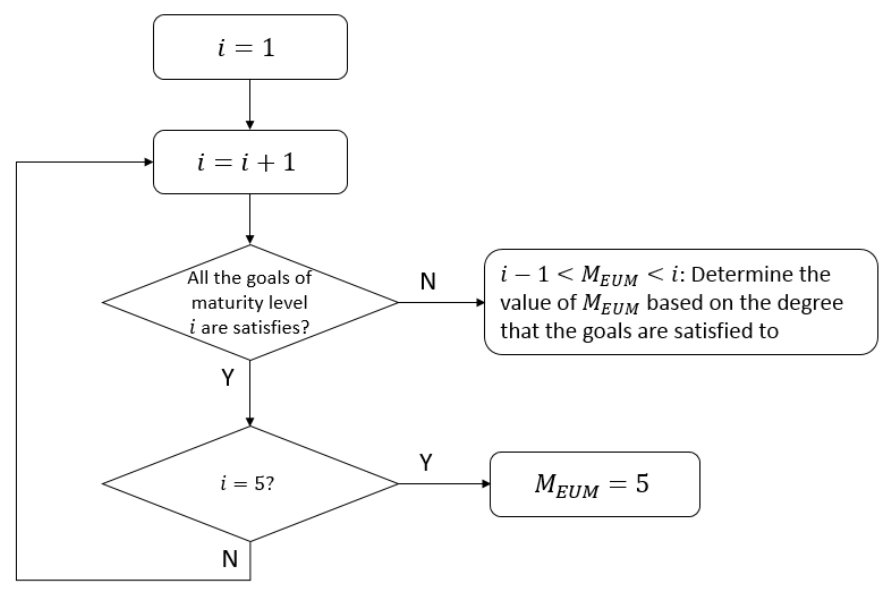

Figure 11 Procedures for evaluating $M_{E U M}$.

Table 7 Evaluation questionnaire for maturity level 2

\begin{tabular}{|l|l|l|c|}
\hline \multicolumn{1}{|c|}{ Goals } & To which degree the goal is satisfied? \\
\cline { 2 - 4 } & Not at all & Partly & Very well \\
\hline The PRA needs to be documented in a well-organized report. & & & \\
& & & \\
\hline $\begin{array}{l}\text { The report should contain the necessary information for identifying } \\
\text { sources of EU, including completeness uncertainty, model structural } \\
\text { uncertainty and parametric uncertainty. }\end{array}$ & $\times$ & & \\
\hline $\begin{array}{l}\text { Potential sources of EU need to be identified through an analysis } \\
\text { conducted by qualified experts. }\end{array}$ & & & \\
\hline $\begin{array}{l}\text { The analysis needs to cover completeness uncertainty, model structural } \\
\text { uncertainty and parametric uncertainty. }\end{array}$ & & $\times$ & \\
\hline $\begin{array}{l}\text { The results of the analysis need to be confirmed by peer reviews from } \\
\text { independent experts. }\end{array}$ & & & \\
\hline $\begin{array}{l}\text { The impact of the EU on the calculated risk indexes needs to be } \\
\text { analyzed by qualified experts. }\end{array}$ & & & $\times$ \\
\hline $\begin{array}{l}\text { The analysis should cover completeness uncertainty, model structural } \\
\text { uncertainty and parametric uncertainty. }\end{array}$ & & $\times$ & \\
\hline $\begin{array}{l}\text { Decision making considers both the calculated risk index and the EU in } \\
\text { the PRA. }\end{array}$ & $\times$ & & \\
\hline
\end{tabular}




\subsection{Determine $\alpha_{e}$}

The value of $\alpha_{e}$ can be determined from $M_{E U M}$ using Eq. (14). The parameter $K$ is determined using the indifference method in Sect. 4.3. For this, empirical data of $\beta_{i}, i=1,2, \cdots, 5$, are elicited from three decision makers (DMs) using the indifference method illustrated in Sect. 4.3, as shown (Table 8). Based on the empirical data in Table 8, the value of $K$ is estimated by solving the least squares minimization problem in Eq. (15):

$$
\hat{K}=1.4975 \text {. }
$$

The fitted model is shown in Figure 12. It can be seen from Figure 12 that the parameters in (18) correspond to EUproneness. According to Eq. (14), we have

$$
\begin{aligned}
\alpha_{e} & =K\left(\frac{1}{M_{E U M}-1}-\frac{1}{4}\right) \\
& =1.4975 \times\left(\frac{1}{1.6-1}-\frac{1}{4}\right)=2.1215 .
\end{aligned}
$$

Table 8 Empirical data from three decision makers

\begin{tabular}{|c|c|c|c|}
\hline & DM 1 & DM 2 & DM 3 \\
\hline$\beta_{1}$ & 0.5 & 0.5 & 0.5 \\
\hline$\beta_{2}$ & 0.1 & 0.2 & 0.25 \\
\hline$\beta_{3}$ & 0.01 & 0.05 & 0.03 \\
\hline$\beta_{4}$ & 0.001 & 0.002 & 0.025 \\
\hline$\beta_{5}$ & 0 & 0 & 0 \\
\hline
\end{tabular}

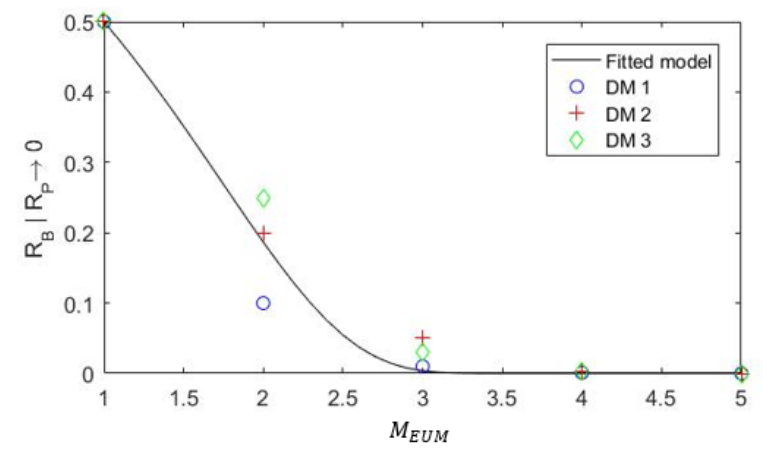

Figure 12 Fitted model V.S. empirical data.

\subsection{Results and discussions}

Substituting Eqs. (17) and (18) into Eqs. (8) and (14), the value of the belief risk index can be calculated:

$$
\begin{aligned}
\operatorname{Risk}_{B} & =\Phi\left(\frac{\Phi^{-1}\left(\operatorname{Risk}_{P}^{*}\right)}{\sqrt{1+\left(\alpha_{e} \cdot \Phi^{-1}\left(\text { Risk }_{P}^{*}\right)\right)^{2}}}\right) \\
& =\Phi\left(\frac{-4.3857}{\sqrt{1+(2.1215 \cdot(-4.3857))^{2}}}\right) \\
& =0.3197 .
\end{aligned}
$$


This Figure shows the belief degree on the occurrence of the consequence of core meltdown, considering both the prediction of the PRA model and the EU in the PRA. As discussed in Sect. 4.2, Risk $k_{B}=0.5$ indicates maximum EU on the results of the PRA. Since Risk $k_{B}$ is close to the value of 0.5 , little confidence can be put on the results of the PRA. This is because, as shown in Sect. 5.3, the EUM of the PRA is of very low level ( $M_{E U M}=1.6$, i.e., the maturity level is between Uncontrolled and Unmanaged). From Table 2 and Table 3, it can be seen that there is large EU in the PRA, which severely impacts the trust on the result of the PRA and makes the decision maker less confident on the result of the PRA. Therefore, the PRA model predicts Risk $_{P}^{*}=5.78 \times 10^{-6}$ but Risk $_{B}=0.3197$, due to the EU on the PRA model.

Figure 13 investigates the influence of EU on the Risk $k_{B}$. The PRA model result Risk $_{P}^{*}$ is fixed to be $\operatorname{Risk}_{P}^{*}=5.78 \times 10^{-6}$ and $M_{E U M}$ level is increased from Initial level to Accurate level. It can be seen that in general, $\operatorname{Risk}_{B} \geq$ Risk $_{P}^{*}$ (strictly speaking, this conclusion holds when Risk $_{P}^{*} \leq 0.5$, which covers most cases in practical

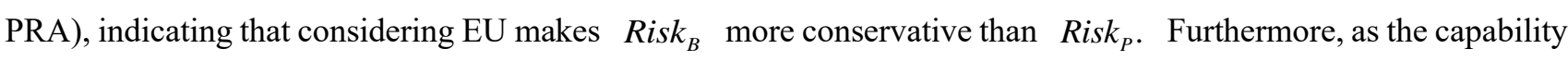
for EU management improves, Risk $k_{B}$ approaches the PSA result Risk $_{P}^{*}$. This indicates an ideal case: when no EU exists in the PRA, we can trust the prediction of the PRA model.

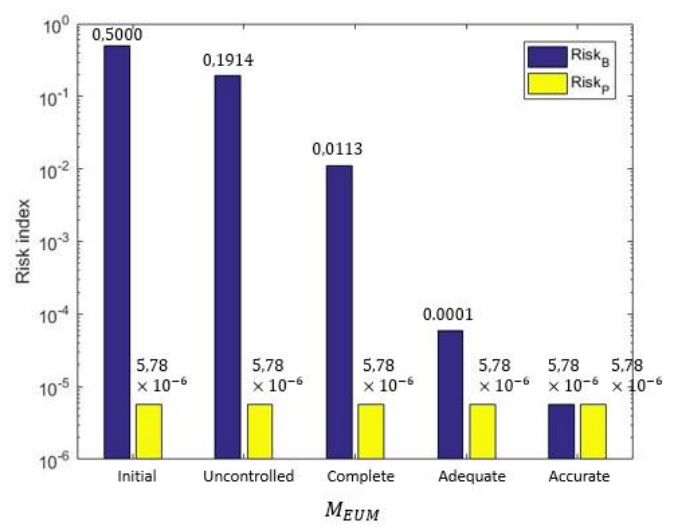

Figure 13 The values of Risk $_{B}$ at different levels of maturity.

Figure 13 shows that the belief risk index is able to integrate the prediction of the PRA model with the EU in the PRA. In this sense, it provides a more complete description of the risk being analyzed. The evaluation of Risk can also be used to support planning improvement activities for reducing EU. For example, the $M_{E U M}$ maturity level for the NPP PRA process is 1.6. As shown in Table 7, three goals associated with maturity level 2 (Uncontrolled) were not fully satisfied. These unsatisfied goals should be the primary improvement directions for improving the EU management capability. Then, further efforts should be made to satisfy the goals defined in higher 
maturity levels (Complete, Adequate and Accurate), until the degree of EU and corresponding Risk $k_{B}$ meets the requirements of the decision problem.

\section{Conclusions}

Epistemic uncertainty in PRA is still a hot topic for methodology development and practical solutions, because of its relevance to the decision making that follows. For practical purposes, closed and definite solutions to the problem do not exist and probably will never exist. Sound and feasible solutions should be the target of any development. In this work, we have developed a maturity model to quantify the capability of a PRA process to manage EU from different sources. Based on the MM-EUM, an integrated risk index, called belief risk index, has been introduced to account for the collective effect of EU in the risk assessment. An indifference method has been proposed for the evaluation of the belief risk index. Practical application was performed on a flooding PRA of an NPP. The results show that the belief risk index is able to consider EU in the PRA model and provides a more complete description of the risks.

A limitation of the current work is that it considers only static PRA models (c.f., fault trees, event trees). In practice, however, both the structure of the PRA model and its parameters can be time-dependent. Extending the MM-EU and the belief risk index to time-dependent models is an interesting future research direction. It should also be noted that this paper is based on the ideas of modeling epistemic uncertainty by probability distributions. There are, however, a lot of discussions and even objections in the epistemic uncertainty quantification community regarding using probability distributions for modelling epistemic uncertainty. One of the main criticism is that, a quantify subject to epistemic uncertainty is not inherently a random variable. Using probability distributions to describe it is only a result of biased perspective of decision makers, and might amply the associated uncertainty. ${ }^{33}$ Besides, it has been long argued that epistemic uncertainty has some unique features that cannot be handled properly by probability distributions. For example, in uncertainty assessment of nuclear weapons, both presence of positive evident that the weapons will work, and absence of evident they will not work are relevant in the analysis ${ }^{34}$. This particular feature could be better captured by evidence theory than probability distributions. ${ }^{34}$ Despite these criticisms, probability theory has still been widely used to quantify epistemic uncertainty in literature, mainly due to its convenience of application and theoretical soundness. ${ }^{13,21}$ In future researches, alternative theories to handle uncertainty, e.g., evidence theory, possibility theory, interval analysis, can also be considered to develop other types of belief risk indexes. 


\section{Acknowledgement}

The authors would like to thank EDF R\&D for providing the information of the case study and Ms. Dominique Vasseur for the related explanations. The authors would like to thank the two anonymous reviewers for their useful comments and suggestions to an earlier version of this article. The work on this article was performed in part while Dr. Roger Flage was visiting CentraleSupélec in the period February-March 2018. He would like to acknowledge the financial support from CentraleSupélec, as well as his co-author Professor Enrico Zio for making his stay possible and memorable. Dr. Zhiguo Zeng would like to thank his son, Zhuochen Zeng, who arrives during the revision of this paper, for making the revision much longer and harder.

\section{References}

1. Yazdi M. A perceptual computing-based method to prioritize intervention actions in the probabilistic risk assessment techniques. Quality and Reliability Engineering International. 2020;36(1):187-213.

2. Zeng Z, Kang R, Wen M, Zio E. Uncertainty theory as a basis for belief reliability. Information Sciences. 2018;429:26-36.

3. Commission UNR. Reactor safety study: An assessment of accident risks in US commercial nuclear power plants. Vol $88 ; 1975$.

4. Hora S, Iman R. Expert opinion in risk analysis: the NUREG-1150 methodology. Nuclear Science and Engineering. 1989;102(4):323-331.

5. Kaplan S, Garrick G. On the quantitative definition of risk, Risk Analysis. vol; 1981

6. Helton JC, Hansen CW, Swift PN. Performance assessment for the proposed high-level radioactive waste repository at Yucca Mountain, Nevada. Reliability engineering \& systems safety. 2014;122.

7. Paté-Cornell ME. Uncertainties in risk analysis: Six levels of treatment. Reliability Engineering \& System Safety. 1996;54(2-3):95-111.

8. Commission NR. Guidance on the treatment of uncertainties associated with PRAs in risk - informed decision making; draft report for comments (NUREG - 1855, rev. 1). Washington DC. 2013.

9. Knight FH. Risk, uncertainty and profit: Courier Corporation; 2012.

10. Wynne B. Uncertainty and environmental learning: reconceiving science and policy in the preventive paradigm. Global environmental change. 1992;2(2):111-127.

11. Smithson M. Ignorance and science: Dilemmas, perspectives, and prospects. Knowledge. 1993;15(2):133-156.

12. Spiegelhalter DJ, Riesch H. Don't know, can't know: embracing deeper uncertainties when analysing risks. Philosophical Transactions of the Royal Society A: Mathematical, Physical and Engineering Sciences. 2011;369(1956):4730-4750.

13. Apostolakis G. The concept of probability in safety assessments of technological systems. Science. 1990;250(4986):1359-1364.

14.Zeng Z, Kang R, Wen M, Zio E. A model-based reliability metric considering aleatory and epistemic uncertainty. IEEE Access. 2017;5:15505-15515.

15. Aven T, Steen R. The concept of ignorance in a risk assessment and risk management context. Reliability Engineering \& System Safety. 2010;95(11):1117-1122.

16. Kazemi R, Mosleh A. Improving default risk prediction using Bayesian model uncertainty techniques. Risk Analysis: An International Journal. 2012;32(11):1888-1900.

17.Jin H, Lundteigen MA, Rausand M. Uncertainty assessment of reliability estimates for safety-instrumented systems. Proceedings of the Institution of Mechanical Engineers, Part O: Journal of risk and reliability. 2012;226(6):646-655.

18. Kukhotskyi O, Dybach O, Iešmantas T. Methodology for PSA Uncertainty Estimation and Application in RiskInformed Decision-Making. Nuclear and Radiation Safety. $2017(4$ (76)):22-27.

19. Bjerga T, Aven T, Flage R. Completeness Uncertainty: Conceptual Clarification and Treatment. Knowledge in Risk Assessment and Management. 2018:127.

20.Zeng Z, Zio E. Dynamic risk assessment based on statistical failure data and condition-monitoring degradation data. IEEE Transactions on Reliability. 2018;67(2):609-622. 
21.Droguett EL, Mosleh A. Integrated treatment of model and parameter uncertainties through a Bayesian approach. Proceedings of the Institution of Mechanical Engineers, Part O: Journal of Risk and Reliability. 2013;227(1):4154.

22.López Droguett E, Mosleh A. Bayesian treatment of model uncertainty for partially applicable models. Risk Analysis. 2014;34(2):252-270.

23.Zio E, Apostolakis G. Two methods for the structured assessment of model uncertainty by experts in performance assessments of radioactive waste repositories. Reliability Engineering \& System Safety. 1996;54(2-3):225-241.

24.Draper D. Assessment and propagation of model uncertainty. Journal of the Royal Statistical Society: Series B (Methodological). 1995;57(1):45-70.

25.Droguett EL, Mosleh A. Bayesian methodology for model uncertainty using model performance data. Risk Analysis: An International Journal. 2008;28(5):1457-1476.

26. Figini S, Giudici P. Credit risk assessment with Bayesian model averaging. Communications in Statistics-Theory and Methods. 2017;46(19):9507-9517.

27. Huo W, Li Z, Wang J, Yao C, Zhang K, Huang Y. Multiple hydrological models comparison and an improved Bayesian model averaging approach for ensemble prediction over semi-humid regions. Stochastic environmental research and risk assessment. 2019;33(1):217-238.

28. Wang G, Jia R, Liu J, Zhang H. A hybrid wind power forecasting approach based on Bayesian model averaging and ensemble learning. Renewable Energy. 2020;145:2426-2434.

29. Riley ME, Grandhi RV. Quantification of model-form and predictive uncertainty for multi-physics simulation. Computers \& structures. 2011;89(11-12):1206-1213.

30. Mosleh A, Apostolakis G. The assessment of probability distributions from expert opinions with an application to seismic fragility curves. Risk analysis. 1986;6(4):447-461.

31.Park I, Grandhi RV. A Bayesian statistical method for quantifying model form uncertainty and two model combination methods. Reliability Engineering \& System Safety. 2014;129:46-56.

32. Ahmadisharaf E, Benham BL. Risk-based decision making to evaluate pollutant reduction scenarios. Science of The Total Environment. 2020;702:135022.

33.Pedroni N, Zio E, Pasanisi A, Couplet M. A critical discussion and practical recommendations on some issues relevant to the nonprobabilistic treatment of uncertainty in engineering risk assessment. Risk Analysis. 2017;37(7):1315-1340.

34. Helton JC, Johnson JD. Quantification of margins and uncertainties: Alternative representations of epistemic uncertainty. Reliability Engineering \& System Safety. 2011;96(9):1034-1052.

35. Hao Y, Rong X, Lu H, Xiong Z, Dong X. Quantification of margins and uncertainties for the risk of water inrush in a karst tunnel: representations of epistemic uncertainty with probability. Arabian Journal for Science and Engineering. 2018;43(4):1627-1640.

36. Flage R, Aven T, Berner CL. A comparison between a probability bounds analysis and a subjective probability approach to express epistemic uncertainties in a risk assessment context-A simple illustrative example. Reliability Engineering \& System Safety. 2018;169:1-10.

37. Kang R, Zhang Q, Zeng Z, Zio E, Li X. Measuring reliability under epistemic uncertainty: Review on nonprobabilistic reliability metrics. Chinese Journal of Aeronautics. 2016;29(3):571-579.

38.Xie C, Li G, Wei F. An integrated QMU approach to structural reliability assessment based on evidence theory and kriging model with adaptive sampling. Reliability Engineering \& System Safety. 2018;171:112-122.

39. Toscani N, Grassi F, Spadacini G, Pignari SA. A possibilistic approach for the prediction of the risk of interference between power and signal lines onboard satellites. Mathematical Problems in Engineering. 2018;2018.

40.Dutta P. Modeling Aleatory and Epistemic Uncertainty in Human Health Risk Assessment. Cybernetics and Systems. 2020:1-21.

41.Zhang Q, Zeng Z, Zio E, Kang R. Probability box as a tool to model and control the effect of epistemic uncertainty in multiple dependent competing failure processes. Applied Soft Computing. 2017;56:570-579.

42. Liu H, Jiang C, Xiao Z. Efficient uncertainty propagation for parameterized p-box using sparse-decompositionbased polynomial chaos expansion. Mechanical Systems and Signal Processing. 2020;138:106589.

43. Wang X, Geng X, Wang L, Wang R, Chen X, Fan W. Time-dependent reliability-based dimensional synthesis for planar linkages with unknown but bounded joint clearances. Journal of Mechanical Design. 2018;140(6).

44. Chen X, Wang X, Qiu Z, Wang L, Li X, Shi Q. A novel reliability-based two-level optimization method for composite laminated structures. Composite Structures. 2018;192:336-346.

45.Paulk M. Capability maturity model for software. Encyclopedia of Software Engineering. 2002.

46. Schwer LE. Guide for verification and validation in computational solid mechanics. 2009.

47. Oberkampf WL, Pilch M, Trucano TG. Predictive capability maturity model for computational modeling and simulation: Sandia National Laboratories Albuquerque, NM; 2007. 
48.Zio E, Di Maio F, Tong J. Safety margins confidence estimation for a passive residual heat removal system. Reliability Engineering \& System Safety. 2010;95(8):828-836.

49. Keeney RL, Von Winterfeldt D. Eliciting probabilities from experts in complex technical problems. IEEE Transactions on engineering management. 1991;38(3):191-201.

50. Melchers RE, Beck AT. Structural reliability analysis and prediction: John Wiley \& Sons; 2018.

51.Bani-Mustafa T, Zeng Z, Zio E, Vasseur D. A practical approach for evaluating the strength of knowledge supporting risk assessment models. Safety Science. 2020;124:104596. 